\title{
Rumours swirl about Trump's science adviser pick
}

\section{Climate sceptic William Happer and ardent critic of academia David Gelernter have met with the president.}

\section{Alexandra Witze \& Jeff Tollefson}

20 January 2017

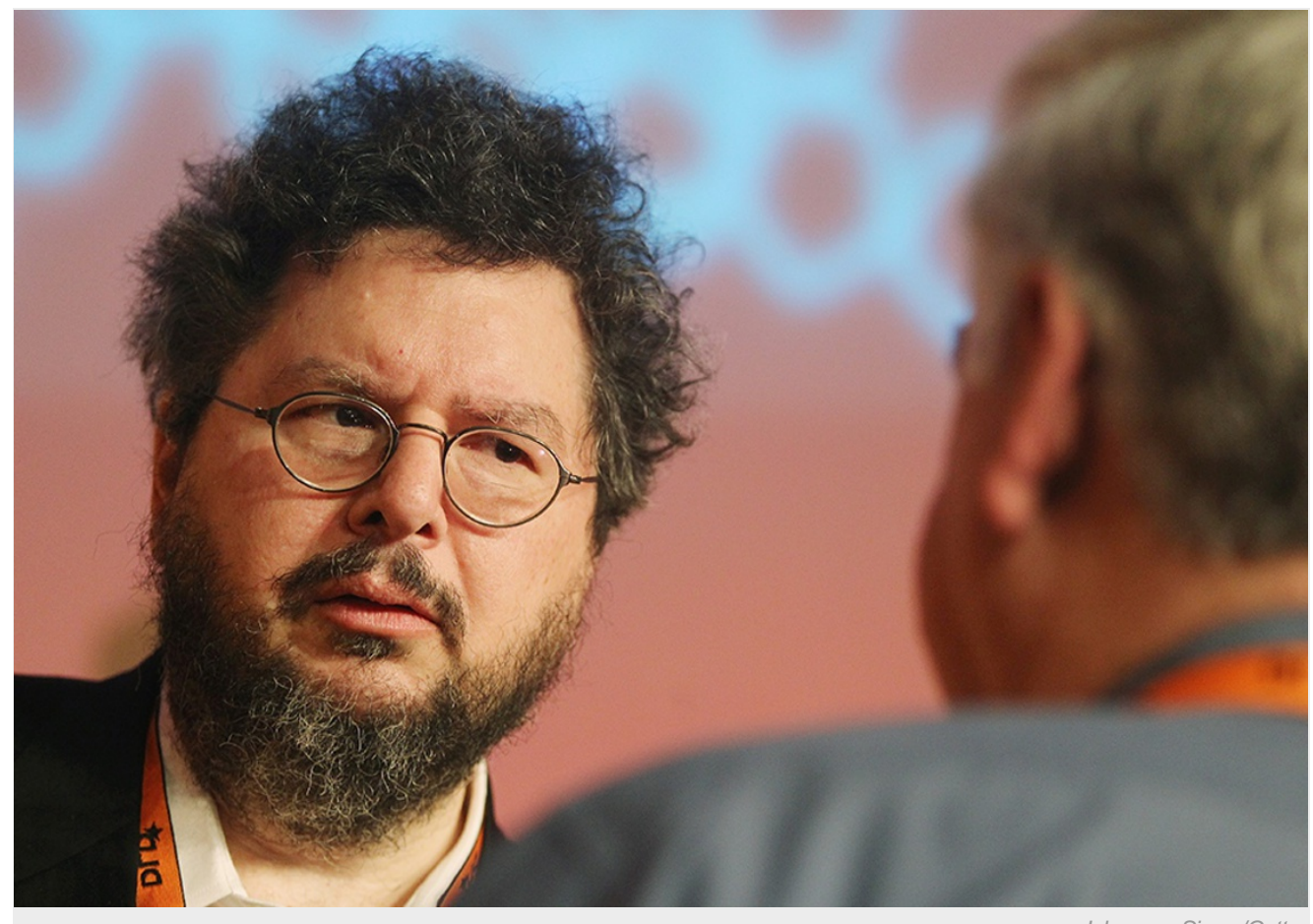

Johannes Simon/Getty

David Gelernter sees a gap in understanding between scientists and the public.

US President Donald Trump has met with two rumoured front-runners for the role of White House science adviser.

Trump met with David Gelernter — a computer scientist at Yale University in New Haven, Connecticut, and a critic of liberal academia — on 16 January. And on 13 January, Trump met with William Happer, a physicist at Princeton University in New Jersey who rejects the notion that carbon dioxide emissions from human activities will cause dangerous levels of global warming. Several media reports have identified the two men as contenders for the science-adviser job.

Gelernter told Nature in an e-mail that his meeting with Trump was "wide-ranging \& informal", adding that the president is "not just sharp; he's thoughtful". Happer says that he did not discuss the science-adviser post with the president, but did speak to him about science and technology.

Still, the meetings have sparked speculation that Trump could soon pick a science adviser who would also lead the White House Office of Science and Technology Policy. Most of the previous presidential science advisers have been physicists — including Barack Obama's choice, John Holdren.

"The science adviser must cover a huge range of issues, and in order to do that you have to have a very broad set of contacts across the disciplines," says Andrew Rosenberg, director of the Center for Science and Democracy at the Union of Concerned Scientists in Cambridge, Massachusetts. "If you have someone who is a bit of an iconoclast, it seems unlikely that they would have that ability."

\section{Science under the lens}

Gelernter is a pioneer in the field of parallel processing, in which multiple processors run simultaneously to speed up calculations. In the early 1980s, he helped to develop a parallel-programming system he named Linda, after a star of pornographic films. It became the basis for many subsequent programming systems. 
He told Nature that the Trump team has not offered him a job, but added that the next science adviser will face a daunting challenge: not only educating the public about science, but capturing the public imagination.

"The gap between the public \& the sciences has grown so gigantic, it's dangerous," he said. "People rely every day, sometimes every hour, on computers \& the net — often without knowing even vaguely how they work. The 'educated public' no longer has the vaguest idea what physics is doing. Which means, in turn, that science \& tech will increasingly be the work of an elite priesthood that does exactly what it likes."

He added: "Science has never been less articulate, less interested in communicating its own excitement and wonder and fascination."

In his own work, Gelernter has looked to the frontiers of technology. His 1991 book Mirror Worlds (Oxford University Press) imagines computing of the future, and a company he founded in New Haven as Mirror Worlds Technologies later sued Apple for reported patent infringement. In the mid-1990s, Gelernter helped to develop a concept known as lifestreams, meant to sort a person's information into a time-ordered stream something akin to a Twitter or Facebook feed today.

Being a public face of the future of technology proved dangerous. In 1993, Gelernter was seriously hurt when a package sent by Unabomber Ted Kaczynski exploded in his office.

Gelernter has criticized the field of artificial intelligence as underperforming, and modern academia as a broken system. His 2012 book America-Lite: How Imperial Academia Dismantled Our Culture (And Ushered in the Obamacrats) (Encounter Books) excoriates liberalism on campus. In it, he also writes that Obama was "oblivious to the gathering scientific doubts" about climate change. In October, Gelernter appeared on the Fox News television channel in support of Trump.

The computer scientist has also stirred controversy by proposing to limit the use of review panels when funding scientific research, says Michael Lubell, a physicist at the City College of New York. Gelernter has suggested replacing such panels with online tools where researchers could post ideas and managers could choose which ones to fund.

"I don't criticize him for not being well intentioned — he believes that this approach will lead to more robust research and development," Lubell says. "It's just that he is very much outside the mainstream."

\section{Warm thoughts}

Happer, an emeritus professor at Princeton, is no stranger to government: he directed energy research at the US Department of Energy from 1991 to 1993 and is a long-time member of JASON, a US defence advisory group.

$\mathrm{He}$ is also a well-known critic of mainstream climate science and as such, a frequent target of environmental activists.

In 2015, the environmental group Greenpeace UK announced that it had caught Happer in a sting operation. Greenpeace officials, posing as representatives of an unnamed Middle Eastern oil company, offered Happer money to write a report on the benefits of increasing atmospheric levels of $\mathrm{CO}_{2}$ - while keeping the funding source a secret. Happer agreed, and maintains that he did nothing wrong. He says that he told the 'oil company' officials that any payments should be sent to the $\mathrm{CO} 2$ Coalition, a US non-profit organization that promotes "the important contribution made by carbon dioxide to our lives and the economy".

"My views are that the whole climate hysteria is greatly overblown," Happer told Nature. "I really do believe more $\mathrm{CO} 2$ will be good for the world." That contradicts decades of climate-change research that has linked rising greenhouse-gas levels in the atmosphere to everything from shifting ecosystems to rising seas.

Although his views on climate change are outside the mainstream, colleagues say that Happer is a solid physicist who has excelled at previous posts. "People are complex. That's the only way to understand it," says Lyman Page, who chairs the physics department at Princeton. "He cares deeply about the country, and he is a very principled person."

Nature | doi:10.1038/nature.2017.21336 